\title{
AMAMENTAÇÃO NO ALOJAMENTO CONJUNTO
}

\author{
Maternal breastfeeding in rooming-in
}

Maria Cecilia dos Santos Marques ${ }^{(1)}$, Adriana de Medeiros Melo(2)

\begin{abstract}
RESUMO
Objetivo: avaliar a amamentação em bebês do Alojamento Conjunto, identificar e avaliar as dificuldades no início do aleitamento materno. Métodos: estudo transversal descritivo. A amostra foi constituída de 100 binômios mãe/recém-nascidos, em maternidade pública estadual que atende ao parto de alto risco pelo Sistema Único de Saúde. Utilizando protocolo do Fundo das Nações Unidas para Infância para observação e avaliação da mamada, foram registrados os comportamentos de cada dupla, computando-se a freqüência de comportamentos desfavoráveis ao aleitamento materno exclusivo. Além disso, foram coletados dados no prontuário do bebê e aplicado um questionário com as mães. Resultados: a freqüência de binômios que apresentaram comportamentos sugestivos de sérias dificuldades (escore ruim) com o inicio do aleitamento materno variou entre $16 \%$ e $44 \%$, conforme o aspecto da mamada avaliada. As dificuldades encontradas foram: adequação da sucção; má posição corporal da mãe e do bebê durante a mamada; o aspecto da anatomia das mamas; respostas da dupla e afetividade. Estas dificuldades foram mais significantes quando o parto foi cirúrgico $(p<0,05)$ e a mãe não recebeu orientações sobre aleitamento materno $(p<0,05)$. Conclusão: foi encontrado grande número de binômios mãe/bebê com comportamento sugestivo de dificuldades iniciais na amamentação. Também foi observada a necessidade da realização de um trabalho de orientação junto às mães o quanto antes, a fim de que estas adquiram uma técnica correta de amamentação.
\end{abstract}

DESCRITORES: Alojamento Conjunto; Aleitamento Materno; Comportamento Materno

\section{INTRODUÇÃo}

A amamentação é o acontecimento mais importante dos primeiros meses de vida do bebê: ela reforça $o$ vinculo entre mãe e filho, promove o aumento dos anticorpos e o ganho de peso, assim como, ajuda no desenvolvimento das estruturas orais como lábios, língua, bochechas, palato duro e mole, responsáveis pelo funcionamento adequado das funções de respiração, sucção, deglutição, mastigação e fonoarticulação e propicia o padrão nasal de respiração ${ }^{1-7}$. É ainda a principal alternativa nutricional para a criança, que associa elementos fundamentais da nutrição correta: alimento, saúde e cuidados e previne a desnutrição ${ }^{8-10}$. Além desses aspectos, o uso do leite materno também previne a contração de doenças infecciosas, principalmente

(1) Acadêmica do curso de Fonoaudiologia da Universidade Estadual de Ciências da Saúde de Alagoas.

(2) Fonoaudióloga; Docente da Faculdade de Fonoaudiologia da Universidade Estadual de Ciências da Saúde de Alagoas; Mestranda em Saúde da Criança e do Adolescente pela Universidade Federal de Pernambuco. diarréias e infecções respiratórias, importantes causas de mortalidade infantil ${ }^{7-14}$. Contribui também para a estruturação psico-emocional da criança ${ }^{7}$. Para a mãe, favorece a perda de peso adquirido na gestação, auxilia no processo de involução uterina, com redução de perda de sangue, e diminui a probabilidade da ocorrência de câncer de mama ${ }^{2}$.

Por desconhecimento da importância da amamentação desde o pré-natal; além dos fatores de ordem biológica, psicológica e sócio-culturais; o bebê pode fazer uma pega incorreta no peito, ocorrendo uma ordenha ineficiente ${ }^{9,15}$. Por isso, um dos interesses da Fonoaudiologia é que esta função seja realizada assim que o bebê nasce, de modo eficiente e prazeroso para o binômio mãe/bebê, desta forma, facilita a adequação das funções orais auxiliando na prevenção das alterações de linguagem e das estruturas orofaciais ${ }^{1,2,16}$.

O pesquisador Edith Jackson, com o propósito de humanizar o nascimento, de forma a trazer o bebê para junto da mãe e promover o aleitamento materno, criou o experimento conhecido como "Projeto Alojamento Conjunto". Assim, em 1946, no 
Grace New Haven Hospital, foi inaugurada a primeira "rooming-in unit" com 4 leitos e 4 berços ${ }^{17}$. 0 Alojamento Conjunto (AC) consiste no sistema hospitalar em que o recém-nascido (RN) sadio permanece ao lado da mãe, durante sua hospitalização pós-parto, quando Ihes serão prestados todos os cuidados assistenciais e de orientação necessários à saúde desse binômio mãe-filho ${ }^{18,19}$.

Em 1971, no Hospital Distrital de Brasília o professor Ernesto Silva implantou a primeira experiência de utilização de AC no Brasil. Em 1977, na V Reunião de Perinatologia do Ministério da Saúde, foi recomendado que os recém-nascidos sem risco devessem ficar ao lado das mães, e não mais em berçários ${ }^{20}$. Em 1987, foi estabelecido, pelo Ministério da Saúde, o Programa Nacional de Incentivo ao Aleitamento Materno (PNIAM), que utilizou a mídia para divulgação dos benefícios da amamentação. Dois anos depois, em 1989, a Organização Mundial de Saúde (OMS) e o Fundo das Nações Unidas para Infância (UNICEF) elaboraram os "dez passos para o sucesso do aleitamento materno", com a criação da "Iniciativa Hospital Amigo da Criança" (IHAC), título que facilita a verba para os hospitais que seguem rigorosamente este programa, que promove, protege e incentiva o direito à amamentação, a fim de reduzir o desmame precoce e suas conseqüências sobre a morbi-mortalidade infantil ${ }^{21,22}$.

A IHAC propõe ao hospital: definir uma norma de aleitamento materno; não utilização de bicos artificiais ou chupetas; treinamento da equipe de saúde que presta assistência às mães e bebês; orientação e apoio às gestantes e a implantação do alojamento conjunto ${ }^{23}$. Dentre as ações ao aleitamento materno recomendadas, encontra-se a observação de cada dupla mãe/neonato durante uma mamada ${ }^{20}$. Essa atividade tem sido proposta como forma de identificar mães e bebês que necessitam de apoio extra, tendo sido proposto pelo UNICEF um protocolo para orientar essa atividade, em que são apresentados os comportamentos maternos e do recém-nascido desejáveis e outros indicativos de problemas ${ }^{18,20}$. Segundo dados do UNICEF no Brasil, em Alagoas existem apenas 7 Hospitais "Amigo da Criança", sendo que no município de Maceió conta com apenas um hospital que recebe esse titulo ${ }^{24}$.

Nas capitais brasileiras, a mediana de amamentação é de 10 meses. No entanto, a mediana de amamentação exclusiva é de apenas 23 dias, havendo variações regionais, o que demonstra característica importante de problema de saúde pública 6,21,25,26. É interessante ressaltar que o aleitamento é uma estratégia fundamental para a redução da mortalidade infantil e para a melhoria da qualidade da saúde da população, além de não ter custos para a família ${ }^{21}$. No estudo realizado pelo Sistema de Informação da Atenção Básica (SIAB), em 2001, no Brasil, $62,3 \%$ das crianças até 4 meses tem aleitamento materno exclusivo e no estado de Alagoas esse número cai para $49,9 \%{ }^{27}$.

Diante do baixo índice de aleitamento materno exclusivo no Estado de Alagoas e da importância da realização de um estudo que possa identificar os fatores que levam a essa situação, este trabalho tem como objetivo avaliar a amamentação de bebês no Alojamento Conjunto na Maternidade Escola Santa Mônica (MESM), para identificar e avaliar as dificuldades presentes no início do aleitamento materno.

\section{MÉTODOS}

Este é um estudo analítico, com corte transversal e quantitativo, realizado no período de janeiro a maio de 2007, na Maternidade Escola Santa Mônica localizada na cidade de Maceió-AL, instituição de referência para todo o Estado, visto que atende gestantes de alto risco pelo Sistema Único de Saúde (SUS). O Alojamento Conjunto é composto por duas enfermarias: Enfermaria I e II, ambas com cinco quartos. A quantidade de leitos varia de quatro a sete, por quarto.

A amostra foi constituída por 100 binômios mães/recém-nascidos. Foram adotados os seguintes critérios de inclusão: recém-nascidos saudáveis, não gemelares e com peso de nascimento igual ou maior que $2.500 \mathrm{~g}$. Já os critérios de exclusão foram: recém-nascidos prematuros.

Optou-se por realizar todas as entrevistas e observações na Enfermaria II, uma vez que, na Enfermaria I, encontravam-se muitos binômios fora dos critérios de inclusão.

A comparação de características da amostra com a população assistida na maternidade em 2006, ano mais próximo da coleta de dados deste estudo, para o qual existem dados no NHEP Núcleo de Epidemiologia Hospitalar da Maternidade Escola Santa Mônica - indicou que esta pode ser considerada representativa. A média de idade das mães (23,05 na amostra e 24,0 na população), a proporção de partos cesarianos (65\% e $63 \%$ ) e o peso médio das crianças $(3.019 \mathrm{~g}$ e $3.126 \mathrm{~g})$ foram semelhantes.

Inicialmente o termo de consentimento livre e esclarecido foi lido, explicado verbalmente e assinado pelos participantes do estudo. Posteriormente, foram pesquisados dados no prontuário dos recémnascidos e colhidas informações fornecidas pelas mães acerca de orientações recebidas no pré-natal e/ou no Alojamento Conjunto, antecedentes gestacionais, tipo de parto e outros aspectos relacionados à assistência e aos cuidados dirigidos ao neonato $e$ 
a puérpera. Para verificar quais binômios estavam dentro dos critérios de inclusão, as informações foram colhidas durante visitas realizadas em dias da semana e períodos variados, de acordo com a disponibilidade de uma das pesquisadoras.

Para guiar a observação direta do fenômeno de interesse (comportamentos da dupla mãe/recémnascido durante a mamada) e avaliar as respostas maternas e dos neonatos, optou-se pela utilização de um formulário oficial, proposto pelo UNICEF ${ }^{24}$. Este foi adaptado por Carvalhares ${ }^{20}$ e contém uma série de reações classificadas em favoráveis à amamentação ou sugestivas de dificuldades, referentes à posição corporal da mãe e do neonato durante a amamentação, às respostas do binômio ao iniciarem a mamada, à eficiência da sucção, ao envolvimento afetivo entre mãe e filho e às características anatômicas da mama. Este protocolo encontra-se na Figura 1.

Considerou-se como mamada o episódio completo, isto é, desde a decisão da mãe de colocar o recém-nascido no seio até o seu encerramento ${ }^{20}$. Todos os binômios foram observados no período de até 48 horas após a admissão no Alojamento Conjunto.

O protocolo desta pesquisa foi aprovado, em 12 de setembro de 2006, pela comissão de ética do núcleo de ensino e pesquisa da Maternidade Escola Santa Mônica e pelo Comitê de Ética em Pesquisa da Universidade Estadual de Ciências da Saúde de Alagoas - UNCISAL, com protocolo $\mathrm{n}^{\circ} 613$, em 04 de dezembro de 2006.

Os dados foram tabulados no programa Microsoft Office Excel $2003^{28}$. Realizou-se inicialmente a caracterização das mães, de seus filhos e das práticas assistenciais a eles dirigidas na maternidade. Posteriormente, foi computada a freqüência de comportamentos desfavoráveis para cada aspecto da mamada investigada e, de acordo com o número de comportamentos negativos observados, foram criados escores de avaliação. Na Tabela 1, são apresentados os critérios empregados na classificação destes escores (bom, regular e ruim) ${ }^{20}$.

Os dados foram processados pelo aplicativo para microcomputador Statistical Package for the Social Science (SPSS) ${ }^{29}$, versão 13.0. Aplicou-se testes de estatística descritiva, mais especificamente a distribuição das freqüências e das percentagens relativas de cada dado observado. Em relação à associação entre as variáveis estudadas foram utilizados os seguintes testes: teste Qui-Quadrado, com nível de significância de $5 \%(p \leq 0,05)$ e o teste de Correlação Bivariada com o grau de correlacionamento linear de Spearman $(R)$, utilizando o nível de significância de $5 \%(p \leq 0,05)$.

\section{RESULTADOS}

A idade materna variou de 14 a 43 anos, com média de 23,05 e desvio padrão de 6,1 anos; 78 (78\%) viviam com companheiro; $66(66 \%)$ tinham ensino fundamental incompleto; $47(47 \%)$ apresentaram renda familiar mensal de um salário mínimo. No que diz respeito à gestação, $60(60 \%)$ eram primíparas; 45 (45\%) tiveram de quatro a seis consultas pré-natais; 75 (75\%) referiram ter recebido orientações sobre amamentação no alojamento conjunto ou no pré-natal; 65 (65\%) dos partos foram cesáreos.

Os recém-nascidos tinham entre 24 a 48 horas de vida e apresentaram, ao serem admitidos no Alojamento Conjunto, peso médio de $3.019 \mathrm{~g}$ com desvio padrão de $376,7 \mathrm{~g}$ e idade gestacional média de 38,91 semanas com desvio padrão de 0,9. Ainda na admissão, 86 (86\%) dos bebês apresentavam aleitamento materno exclusivo e, ao receberem alta, 92 (92\%) dos bebês apresentavam esse tipo de aleitamento. $O$ tempo médio de permanência no alojamento conjunto foi de 3,56 dias com desvio padrão de 1,3 dias.

Os resultados da avaliação dos comportamentos da mãe e do recém-nascido na mamada constam

Tabela 1 - Critérios para classificação dos escores empregados na avaliação da mamada segundo cada aspecto avaliado

\begin{tabular}{lcccc}
\hline \multirow{2}{*}{ Aspectos avaliados } & \multirow{2}{*}{$\begin{array}{c}\text { No de comportamentos } \\
\text { negativos investigados }\end{array}$} & \multicolumn{3}{c}{$\begin{array}{c}\text { Comportamentos negativos } \\
\text { observados/ Classificação dos escores }\end{array}$} \\
\cline { 3 - 5 } & & Bom & Regular & Ruim \\
\hline Posição mãe/criança & 05 & $0-1$ & $2-3$ & $4-5$ \\
Respostas da dupla & 06 & $0-1$ & $2-3$ & $4-6$ \\
Adequação da sucção & 06 & $0-1$ & $2-3$ & $4-6$ \\
Anatomia das mamas & 04 & 0 & 1 & $2-4$ \\
Afetividade & 03 & 0 & 1 & $2-3$ \\
\hline
\end{tabular}

Fonte: Carvalhares (2003) 


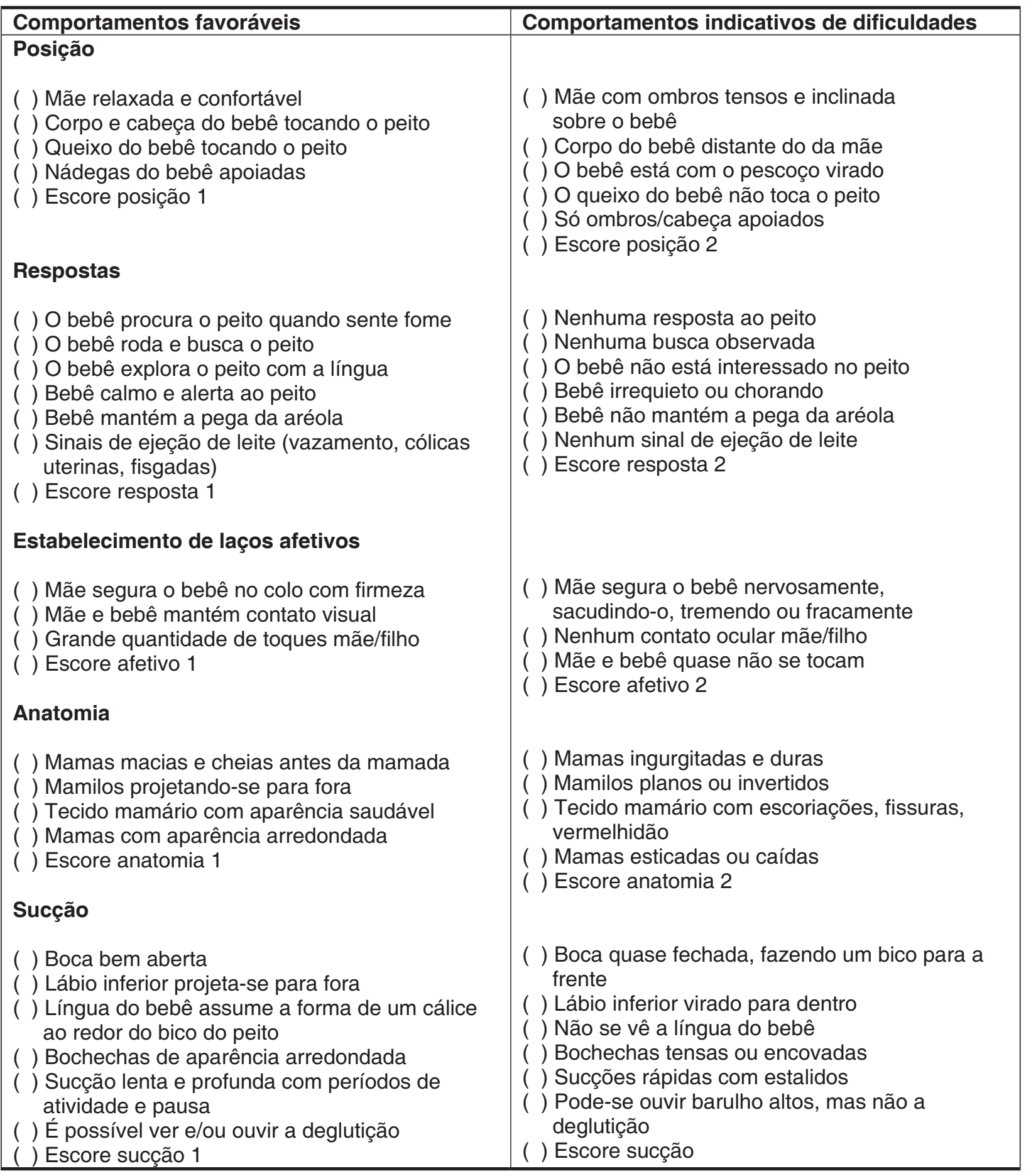

Adaptado do UNICEF por Carvalhares. ${ }^{12}$

Figura 1 - Formulário de observação e avaliação de mamada

da Figura 2. Observou-se que grande parte dos binômios apresentaram escores adequados (bons), indicativos de início satisfatório da amamentação. A ocorrência de escores ruins, ou seja, a presença de diversos comportamentos sugestivos de dificuldades, que poderiam resultar no desmame precoce, foi significativo e ficou entre $6 \%$ e $44 \%$ das duplas.
Os piores resultados foram relativos à adequação da sucção, uma vez que $44 \%$ dos binômios avaliados no estudo apresentaram de quatro a seis dos seis comportamentos negativos analisados (boca quase fechada, lábio inferior voltado para dentro, bochechas tensas ou encovadas, sucções rápidas com estalidos, entre outros). 
Distribuição \% dos binômios mãe/neonato

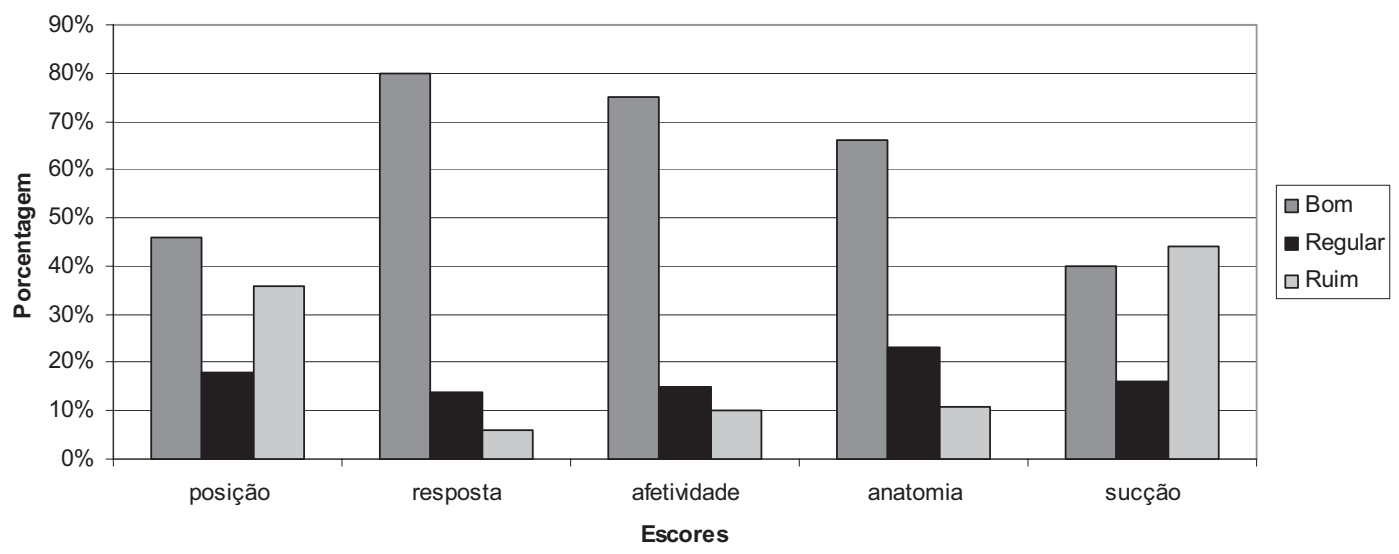

Figura 2 - Distribuição (\%) das duplas mãe/recém-nascido de acordo com os escores relativos à posição corporal, sucção, anatomia das mamas, afetividade e respostas do binômio - Maceió, 2007

A observação da posição corporal da mãe e do recém-nascido durante a mamada revelou que $54 \%$ das duplas (somando-se 18 mães com escore regular e 36 com escore ruim) apresentavam algum tipo de dificuldade, como corpo do bebê distante da mãe, genitora com ombros tensos e inclinados sobre o bebê, ausência do toque do queixo do bebê no peito, entre outros.

Também foram encontrados escores ruins para $34 \%$ das mães (somando-se 23 mães com escore regular e 11 mães com escore ruim) quando analisados os aspectos da anatomia das mamas. Dentre as alterações, citam-se lesão no mamilo, como escoriações, e fissuras mamilares.

Escores ruins também ocorreram para $6 \%$ dos binômios quando se avaliaram determinadas respostas negativas, tais como: neonato inquieto e agitado, o que resulta em dificuldades para manter a pega da aréola, e mãe sem sinais de ejeção de leite.

Com relação à análise dos comportamentos indicativos de afetividade entre mãe e filho, também foi encontrada uma freqüência significativa de $25 \%$ das duplas com respostas negativas (15 duplas com escore regular e $10 \mathrm{com}$ escore ruim). Nestes casos, observou-se que as mães seguravam os bebês de forma tensa, não mantinham contato visual com o filho e quase não o tocavam.

O fato de a mãe receber orientações sobre aleitamento materno associou-se significativamente com os aspectos avaliados de posição corporal $(p=0,00)$, respostas da dupla $(p=0,00)$, afetividade $(p=0,00)$, anatomia das mamas $(p=0,00)$ e adequação da sucção $(p=0,04)$. As mães que não receberam orientações no pré-natal ou no alojamento conjunto apresentaram escores desfavoráveis. Estes dados encontram-se na Tabela 2.
Tabela 2 - Distribuição dos binômios mãe/ neonato segundo escores de avaliação da mamada e recebimento de orientações sobre aleitamento materno - Maceió, 2007

\begin{tabular}{lcc}
\hline \multirow{2}{*}{ Escores } & \multicolumn{2}{c}{ Orientação (\%) } \\
\cline { 2 - 3 } & Recebeu & Não recebeu \\
\hline Posição* & 35 & 11 \\
Bom & 13 & 5 \\
Regular & 27 & 9 \\
Ruim & 75 & 25 \\
Total & & \\
Afetividade & 54 & 21 \\
Bom & 14 & 1 \\
Regular & 7 & 3 \\
Ruim & 75 & 25 \\
Total & 30 & \\
Adequação da sucção" & 10 \\
Bom & 14 & 2 \\
Regular & 31 & 13 \\
Ruim & 75 & 25 \\
Total & 58 & 22 \\
Respostas do neonato & \\
Bom & 12 & 1 \\
Regular & 5 & 2 \\
Ruim & 75 & 25 \\
Total & & \\
Anatomia das mamas & & \\
Bom & 49 & 5 \\
Regular & 17 & 3 \\
Ruim & 9 & \\
Total & 75 & \\
\hline
\end{tabular}

Teste Qui-quadrado (Pearson)

${ }^{*} \mathrm{p}=0,00 ; \S p=0,00 ; \| p=0,04 ; \dagger p=0,00 ; \neq p=0,00$ 
Na Tabela 3, são apresentados os resultados da investigação da existência de associação entre o tipo de parto e os escores desfavoráveis. Os binômios mães/bebês que tiveram partos operatórios associaram-se com piores escores relativos à posição corporal $(p=0,00)$, respostas da dupla $(p=0,00)$,

Tabela 3 - Distribuição dos binômios mãe/ neonato segundo escores de avaliação da mamada e tipo de parto - Maceió, 2007

\begin{tabular}{lcc}
\hline \multirow{2}{*}{ Escores } & \multicolumn{2}{c}{ Tipo de parto (\%) } \\
\cline { 2 - 3 } & Vaginal & Cesariana \\
\hline Posição* & & \\
Bom & 21 & 25 \\
Regular & 6 & 12 \\
Ruim & 8 & 23 \\
Total & 35 & 65 \\
Afetividade & & \\
Bom & 29 & 46 \\
Regular & 2 & 13 \\
Ruim & 4 & 6 \\
Total & 35 & 65 \\
Adequação da sucçãoll & \\
Bom & 18 & 22 \\
Regular & 4 & 12 \\
Ruim & 13 & 31 \\
Total & 35 & 65 \\
Respostas do neonato & \\
Bom & 29 & 51 \\
Regular & 3 & 11 \\
Ruim & 3 & 6 \\
Total & 35 & 65 \\
Anatomia das mamas & \\
Bom & 29 & 37 \\
Regular & 3 & 20 \\
Ruim & 3 & 8 \\
Total & 35 & 65 \\
\hline
\end{tabular}

Teste Qui-quadrado (Pearson)

${ }^{*} p=0,00 ; \S p=0,00 ; \| p=0,04 ; \dagger p=0,00 ; \ddagger p=0,00$ afetividade $(p=0,00)$, anatomia das mamas $(p=0,00)$ e adequação da sucção $(p=0,04)$.

De acordo com a análise de Correlação Bivariada com o grau de correlacionamento linear de Spearman (R), não foram significativas as associações entre as características da mãe (idade, grau de escolaridade e a renda familiar) e os diferentes escores avaliados. Estes dados encontram-se na Tabela 4.

\section{DISCUSSÃO}

O método empregado neste estudo (transversal) não permite relacionar as dificuldades iniciais da amamentação e o processo de manutenção do aleitamento materno exclusivo posterior, o que implica em uma limitação do estudo. Entretanto, é oportuno realizá-lo com enfoque fonoaudiólogico, destacando os aspectos referentes à posição, respostas do neonato, adequação da sucção, afetividade e anatomia das mamas, de modo a relacionar a fisiologia oral do aleitamento materno a possíveis disfunções orais, assim como, sua interferência no início da amamentação nesta população.

Devido à alta rotatividade das duplas no Alojamento Conjunto, a observação das mamadas foi realizada somente uma vez para cada binômio mãe/bebê. Possivelmente, a observação de mais mamadas poderia acarretar em escores diferentes pela influência de fatores como humor da dupla no momento da observação e aprendizado rápido do processo de amamentação por mães ainda inexperientes.

A média de idade das mães foi de 23,05 anos, achado semelhante em outro estudo ${ }^{7}$, em que a média encontrada foi de 25,4 anos. Apesar da idade da mãe ser um fator diretamente relacionado à dificuldade inicial para o estabelecimento da amamentação ${ }^{7,21}$, este dado não foi significativo neste estudo, o que pode ser explicado pelo fato das idades das mães serem semelhantes.

Quanto ao nível de escolaridade, fator que interfere na dificuldade para a amamentação ${ }^{7,12,21}$, a percentagem das mães que apresentaram ensino

Tabela 4 - Associação* entre características da mãe e escores de avaliação da mamada - Maceió, 2007

\begin{tabular}{lccc}
\hline \multirow{2}{*}{ Escores } & Idade das mães & Escolaridade & Renda familiar \\
\cline { 2 - 4 } & $\mathbf{p}$ & $\mathbf{p}$ & $\mathbf{p}$ \\
\hline Posição & 0,30 & 0,10 & 0,60 \\
Respostas & 0,20 & 0,70 & 0,30 \\
Sução & 0,90 & 0,60 & 0,20 \\
Anatomia da mama & 0,90 & 0,50 & 0,50 \\
Afetividade & 0,70 & 0,90 & 0,50 \\
\hline
\end{tabular}

* Resultados não significantes, teste Mann-Whitney U. 
fundamental foi de $66 \%$, dados parecidos com os encontrados em outro estudo, o qual obteve $77 \%$ para a mesma escolaridade ${ }^{7}$. Assim como a idade da mãe, esta variável também não foi significativa, o que se explica pelo fato da maternidade apresentar uma amostragem homogênea, com apenas algumas variações. Poucas mães haviam cursado o ensino médio e apenas uma cursava o ensino superior.

Outra variável estudada, que também não influenciou na dificuldade, foi à renda familiar. Neste estudo, houve predominância das mães que apresentavam renda familiar de até, no máximo, um salário mínimo. Não foram encontrados na literatura estudos que tivessem investigado especificamente essa relação. Porém, em dois estudos, a renda influenciou sobre a duração do aleitamento materno, contribuindo para o aumento da média entre as mães que apresentavam rendimento maior do que dois salários mínimos ${ }^{8,12}$.

Nesta pesquisa os dados apontaram que, somando-se as freqüências de escores regulares e ruins, $20 \%$ a $60 \%$ das duplas mãe/RN apresentaram alguma dificuldade com o início da amamentação em pelo menos um dos aspectos da mamada observada.

Encontrou-se, na literatura especializada, apenas um estudo que pesquisou a prevalência de comportamentos indicativos de problemas com o início da amamentação utilizando o protocolo do UNICEF. Este estudo foi realizado com uma população parecida e a freqüência de dificuldades encontradas, de $18 \%$ a $34 \%{ }^{20}$, foi semelhante aos resultados do presente estudo.

Um trabalho, realizado no Hospital Guilherme Álvaro, investigou dificuldades precoces relacionados à amamentação, porém utilizou outros instrumentos para a observação dos binômios e avaliação das mamadas ${ }^{23}$. A freqüência dos binômios com dificuldades, cerca de $13 \%$, foi menor do que a observada neste estudo, entretanto, deve-se ressaltar que o referido hospital apresenta práticas assistenciais mais adequadas para o início do aleitamento materno quando comparado à maternidade em que foi realizada esta pesquisa.

Os problemas iniciais detectados entre os binômios referem-se principalmente à sucção durante $a$ mamada, que dificulta a pega adequada. Quando o bebê suga apenas o mamilo, aumenta-se a probabilidade de traumas nas mamas, sintomatologia dolorosa para a mãe; mamadas pouco eficientes; frustração materna quanto a quantidade de leite, que repercutem em seu sistema hormonal com conseqüências negativas para a produção de leite e para o crescimento do bebê ${ }^{7}$. Muitos bebês, durante a amamentação, apresentavam sucção desfavorável, ou seja, mantinham a boca quase fechada; o lábio inferior virado para dentro; sucções rápidas e com estalidos e não se via a língua do bebê. Todas essas condições tendem a dificultar a pega adequada da criança ${ }^{7}$.

A associação detectada entre piores escores relativos à sucção da criança e o não recebimento de orientação pode se explicar pela falta de conhecimento dessas mães de que para sugar de maneira eficiente e estimular a produção do leite, a criança precisa abocanhar toda a aréola e não só o bico do peito ${ }^{7}$.

Outra proporção significativa encontrada foi com relação à posição das duplas e a falta de orientação às mães, o que também dificulta a pega adequada causando diversos problemas como os já mencionados anteriormente. De fato, muitas mães amamentavam em posição inadequada, ou seja, mantinham o corpo da criança distante do seu, ficando inclinadas sobre ela. Grande parte dos recém-nascidos precisava virar o pescoço para mamar e, consequentemente, o queixo não tocava o seio materno. Estas condições tendem a dificultar a pega adequada do bebê, comprometendo a amamentação ${ }^{\text {? }}$.

Também foram encontrados resultados significativos com relação à anatomia das mamas e a falta de orientação, o que pode ser explicado pela dificuldade na sucção, levando a escoriações nas mamas, fissuras e vermelhidão, assim como pelo fato de algumas mães apresentarem bico plano ou invertido, o que dificultava a ordenha ${ }^{7}$.

Ainda com relação às respostas do neonato (interesse do bebê pelo seio materno, comportamento desfavoráveis como inquieto ou chorando, pega inadequada da aréola e nenhum sinal de ejeção de leite) e à afetividade, os resultados associaram-se significativamente. Estas dificuldades também foram mais freqüentes quando as mães não receberam orientações e podem ser explicadas pelo fato de que, durante o processo pós-parto, as mães encontram-se mais sensíveis e suscetíveis quanto à sua capacidade de amamentar, o que pode fazer com que elas percam sua confiança ${ }^{6}$.

$\mathrm{Na}$ literatura especializada foi encontrado um estudo que relacionou diretamente as orientações recebidas pelas mães e as dificuldades iniciais. Os resultados foram semelhantes ao deste estudo, em que as mães que não receberam orientações apresentaram maiores dificuldades para adequação da sucção e da posição do binômio ${ }^{7}$.

Outros trabalhos associaram a orientação à duração do aleitamento materno exclusivo e em todos, o conhecimento das mães sobre amamentação foi um dos fatores que contribuíram para a adoção dessa prática $8,26,30$. Durante a gestação, a mulher encontra-se numa situação diferente da 
habitual, com suas dúvidas, inseguranças e medos. Nesse contexto, a mãe pode facilmente perder sua confiança e auto-estima e estar muito propensa a oferecer mamadeira ao seu bebê ${ }^{6}$. Por isso a importância de se realizar a orientação para que não ocorra o desmame precoce.

Outra associação detectada foi entre piores escores relativos à sucção da criança e parto cirúrgico, em que esta associação pode expressar uma relação causal. A cesariana altera as respostas endócrinas na mãe e no bebê no período imediato após o parto, além de provocar dor na mãe e maior sonolência no binômio, condições que retardam e impõem dificuldades nas primeiras mamadas ${ }^{31}$.

Além das dificuldades relativas à sucção do bebê durante a mamada, uma proporção significativa de binômios (35\%) apresentou dificuldade com relação à posição. Alguns estudos concordam que se deve dar atenção especial à forma de posicionar o corpo do $\mathrm{RN}$ em relação ao corpo da mãe. É importante que o corpo do RN esteja sempre voltado para o corpo da mãe com sustentação do quadril, para que esse posicionamento seja mantido ${ }^{7}$. Estes fatores inadequados também foram mais freqüentes quando o parto foi cirúrgico. Esta associação pode ser explicada pelas diferenças nas respostas maternas e do recém-nascido após a cesariana.

Encontrou-se, na literatura, um estudo, realizado no Sudeste do Brasil, que relaciona o parto cirúrgico, o comportamento materno e do recém-nascido durante a mamada que apontou escores piores relativos à posição da dupla e o parto cirúrgico ${ }^{21}$. Outros estudos investigaram a relação entre o tipo de parto e a incidência e duração do aleitamento materno e encontraram menor prevalência de amamentação aos seis meses em crianças nascidas de parto cirúrgico ${ }^{12,30}$.

As explicações para a interrupção da lactação são que a influência do tempo de hospitalização e o padrão de atendimento pós-operatório dificultam o alojamento conjunto e o aleitamento à livre demanda, ou ainda, permite a introdução precoce de outros alimentos na dieta infantil ${ }^{12}$.

É possível que uma das maneiras pela qual a cesariana afete negativamente a duração do aleitamento materno esteja justamente aumentando a ocorrência de dificuldades em seu início, como foi detectado no presente estudo.

Estes resultados, apoiados na literatura acima citada, permitem sugerir que as dificuldades com o início da amamentação sejam incluídas como mais um possível desfecho negativo da prática de realizar cesarianas desnecessárias, ainda presente em hospitais brasileiros.

Uma forma de minimizar essas dificuldades é a realização de um trabalho conjunto da fonoaudiologia e as outras áreas da equipe de saúde, desenvolvendo ações para o aleitamento materno. A maior parte da atuação fonoaudiológica se refere à transmissão de informações as mães, prevenindo e quando necessário, tratando as eventuais intercorrências da lactação. Atuação em bancos de leite para favorecer a substituição de leite a bebês com mães sem possibilidade de amamentar, auxílio para conseguir uma boa pega e avaliação da sucção do recém-nascido para efetivar o aleitamento materno, orientações especificas quando identificada a dificuldade na amamentação e o acompanhamento do aleitamento materno nas diferentes faixas etárias de 0 a 2 anos são ações que podem ser realizadas ${ }^{32}$.

Como produto final da pesquisa, sugere-se um manual (Figuras 3 e 4) de simples leitura para facilitar na orientação das mães, o que pode auxiliar esta população, evitando as dificuldades encontradas nesse trabalho e um possível desmame precoce.

\section{CONCLUSÃO}

O instrumento de avaliação das mamadas foi útil para identificar as dificuldades inicias observadas nesta população, destacando as maiores dificuldades, relação à adequação da sucção, posição corporal da mãe e do recém-nascido durante a mamada, anatomia das mamas e afetividade entre mãe e filho quando as mães não receberam orientações e/ou quando o parto foi cirúrgico. Assim, observou-se a necessidade de orientar as mães para que estas dificuldades possam ser sanadas 0 mais breve possível.

\section{AGRADECIMENTOS}

Agradecemos à colaboração das Fonoaudiólogas Elizângela Dias Camboim, Vivian Passos Lima e Kelly Cristina Lira de Andrade, ao publicitário Lucas de Lima Santos, a Marília Barros, Lucas Gustavo Nogueira Santos e Antônio André Melo Sá Calvacante. 


\section{Por que amamentar?}

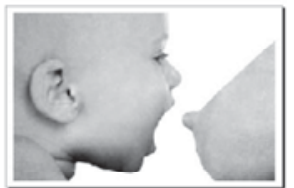

O leite materno contém todas as proteinas, açúcar, gordura, vitaminas e água que o seu bebê necessita para ser saudável.

Além disso, contém determinados elementos que o leite em pó não consegue incorporar tais como anticorpos e glóbulos brancos. Eor issc brancos. Epor isso que oleitematernop co infecçōes, principalmente contra diarréias e infecções respiratórias.

Além de ser mais facilmente digerido, melhora a formação da boca e o alinhamento dos dentes e aumenta a ligação emocional entre a măe e a criança.

É recomendado amamentar o seu bebê até os seis meses apenas com o leite materno.A partir dessa idade outros tipos de alimentos devem ser oferecidos a criança, além do leite materno.

\section{Amamentar tem vantagens também para a mãe}

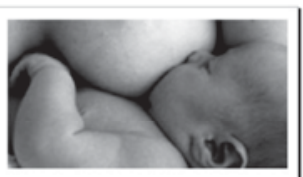

1. A mãe que amamenta sente-se mais segura e menos ansiosa:

2. Amamentar faz queimar calorias e por isso ajuda a mulher a voltar, mais depressa, ao peso que tinha antes de engravidar;

3. Ajuda o útero a regressar ao seu tamanho normal mais rapidamente;

4. A perda de sangue depois do parto acaba mais cedo;

5. Aamamentação protege da osteoporose:

6. A amamentaçăo exclusiva protege da anemia (deficiência de ferro).

7. As mulheres que amamentam demoram mais tempo para ter menstruaçōes, por isso as suas reservas de ferro não diminuem com a hemorragia mensal;

8. Amamentar é muito prático! Não é necessário esterilizar e preparar mamadeiras.

\section{Amamentar também é vantajoso para a família}

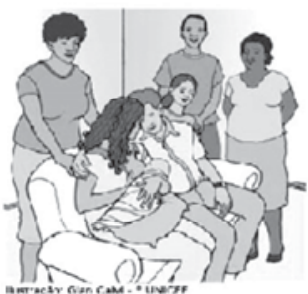

A amamentação é mais econômica para a familia. Basta multiplicar o preço de uma lata de leite em pó pelo número de latas necessárias ao longo da vida da criança somar ainda dinheiro gasto em mamadeirase chupetas.

Figura 3 - Manual de aleitamento para facilitar a orientação das mães

\section{Posicionamento}

na amamentação

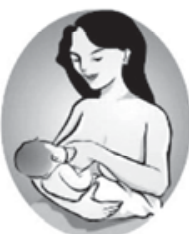

Posição boa do bebê significa que:

Todo corpo do bebê está de encontro ao da mãe;

A boca e o queixo encostam no peito da mãe;

Aboca do bebê está bem aberta:

Não se consegue ver quase nada da aréola (parte escura do peito):

O bebê está relaxado e tranqüilo;

O bebê mama sem fazer barulho:

Amãe não sente dor nos mamilos (só umas dores pequenas no início):

Posição correta da mãe:

Relaxada, confortável, bem apoiada;

Não curvada para trás, nem para frente (os ombros do bebê apoiam-se na curvatura do braço da mãe).

\section{Amamentação na posição}

correta não provoca dor!

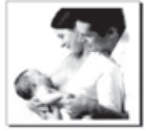

AMAMENTE SEU FILHO!

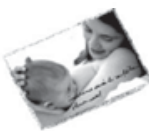

Universidade Estadual de Ciências da Saúde de Alagoas
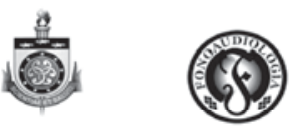
Maria Cecilia Marques
Adriana de Medeiros Melo

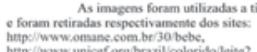

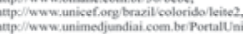

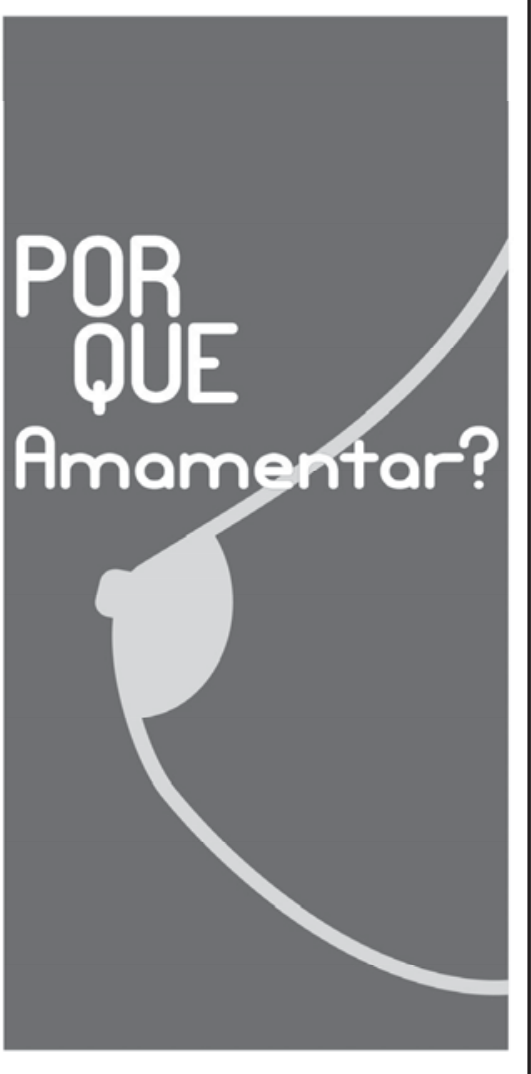

Figura 4 - Manual de aleitamento para facilitar a orientação das mães 


\begin{abstract}
Purpose: to analyze breastfeeding in rooming-in babies, identify and analyze the difficulties in the beginning of breastfeeding. Methods: descriptive transverse study. The sample was made up by 100 mother/new-born binomials, in public maternity hospitals that offer high-risk parturition service. Using a United Nations Children's Fund's protocol to watch and evaluate the sucking, the behavior of the double was recorded, calculating the periodicity of behavious that are unfavourable to the exclusive breastfeeding. Above that, data was collected at baby's handbook and a questionnaire was applied with the mothers during the time of rooming-in internment. Results: the Binominal's frequency, that showed behavious suggesting sever serious difficulties (low score) at the beginning of the breastfeeding, varied between $16 \%$ and $44 \%$, according to the aspect of the evaluated sucking. The most common difficulties were the fitness to the sucking, the bad position of mothers and babies bodies during the sucking and the aspect of the breasts' anatomy. These problems were more important when the parturition was surgical $(p<0.05)$ and the mother did not received any guidance about breastfeeding $(p<0.05)$. Conclusions: high prevalence of the binomials mother/new-born with suggestive behavior of difficulties was identified. We noted the need for a previous instructive job with the mothers as early as possible, so that they may acquire a correct breastfeeding technique.
\end{abstract}

KEYWORDS: Rooming-in Care; Breast Feeding; Maternal Behavior

\section{REFERÊNCIAS}

1. Gamburgo LJL, Munhoz SEM, Amstalden LG. Alimentação do recém-nascido: aleitamento natural, mamadeira e copinho. Fono Atual. 2002; 5(20):39-47.

2. Leite IG, Pinheiro AM, Brum, LRG, Souza SBA. Relação da amamentação com o desenvolvimento do sistema estomatognático. J Bras Fonoaudiol. 2002; 12(3):237-42.

3. Giovannini M, Riva E, Banderali G, Salvione M, Radaelli G, Agostini C. Exclusive versus predominant breastfeeding in Italian maternity wards and feeding practices through the first year of life. J Hum Lact. 2005; 21(3):259-65.

4. Merewood AMA, Philipp BL, Chawla N, Cimo $S$. The baby-friendly hospital initiative increases breastfeeding rates in a US neonatal intensive care unit. J Hum Lact. 2003; 19(2):166-71.

5. Bosi MLM, Machado MT. Amamentação: um resgate histórico. Rev ESP. 2005; 1(1):17-25.

6. Bueno LGS, Teruya KM. Aconselhamento em amamentação e sua prática. J Pediatr. 2004; 80(5):126-30.

7. Sanches MTC. Dificuldades iniciais na amamentação: enfoque fonoaudiológico [mestrado]. São Paulo (SP): Universidade de São Paulo; 2000.

8. Vasconcelos MGL, Lira PIC, Lima MC. Duração e fatores associados ao aleitamento materno em crianças menores de 24 meses de idade no estado de Pernambuco. Rev Bras Saúde Matern Infant. 2006; 6:99-105.
9. Escuder MM, Venâncio SI, Pereira JC. Impact estimates of breastfeeding over infant mortality. Rev Saúde Publ. 2003; 37:319-25.

10. Saleemi MA, Zaman S, Akhtar HZ, Jalil F, Ashraf RN, Hanson LA, et al. Feeding patterns, diarrhoeal illness and linear growth in 0-24 monthold children. J Trop Pediatr. 2004; 50:164-9.

11. Abrão ACFV. Amamentação uma prática que precisa ser aprendida. Pediatr. 2006; 28(2):79-80.

12. Figueiredo MG, Sartorelli DS, Zan TAB, Garcia E, Silva LC, Carvalho FLP, et al. Inquérito de avaliação rápida das práticas de alimentação infantil em São José do Rio Preto, São Paulo, Brasil. Cad Saúde Publ. 2004; 20:172-9.

13. Fuchs SC, Victora CG. Risk and prognostic factors for diarrheal disease in Brazilian infants: a special case-control design application. Cad Saúde Publ. 2002; 18:773-82.

14. Bachrach VR, Schwarz E, Bachrach LR. Breastfeeding and the risk of hospitalization for respiratory disease in infancy: a metanalysis. Arch Pediatr Adolesc Med. 2003; 157(3):237-43.

15. Biancuzzo M. Breastfeeding the newborn: clinical strategies for nurses. St Louis: Mosby; 2002. 560p.

16. Carvalho GD. Amamentação e o sistema estomatognático. In: Carvalho MR, Tamez RN. Amamentação: bases científicas para a prática profissional. Rio de Janeiro: Guanabara Koogan; 2002.

17. Tasca SMT, Almeida EOC, Servilha EAM. Recém-nascido em alojamento conjunto: visão 
multiprofissional. Carapicuíba: Pró-Fono; 2002. p.35-49.

18. UNICEF. Babyfriendly hospital initiative: revised, updated and expanded for integrated care. New York: UNICEF; 2006.

19. Brasil. Ministério da Previdência e Assistência Social. Instituto de Assistência Médica da Previdência Social. Rev Paulist Pediatr. 1985a; 2:28.

20. Carvalhares $\mathrm{MABL}$, Corrêa $\mathrm{CRH}$. Identificação de dificuldades no início do aleitamento materno mediante aplicação de protocolo. J Pediatr. 2003; 79(1):13-20.

21. Araújo MFM. Situações e perspectivas do aleitamento materno no Brasil. In: Carvalho MR, Tamez RN. Amamentação: bases científicas para a prática profissional. Rio de Janeiro: Guanabara Koogan; 2002.

22. Araújo MFM, Otto AFN, Schmitz BAS. Primeira avaliação do cumprimento dos "Dez passos para o sucesso do aleitamento materno" nos hospitais Amigos da Criança do Brasil. Rev Bras Saúde Matern Infant. 2003; 3(4):411-9.

23. VenancioSI. Dificuldades para o estabelecimento da amamentação: o papel das práticas assistenciais das maternidades. J Pediatr. 2003; 79(1):1-2.

24. UNICEF/Brazil. Lista dos Hospitais Amigos da Criança [On line]. 2007. Disponível em: URL: http:// www.unicef.org/brazil/lista.htm

25. Oliveira LD, Giugliani ERJ, Santo LCE, França MCT, Weigert EML, Kohler CVF, et al. Effect of intervention to improve breastfeeding technique on the frequency of exclusive breastfeeding and lactation-related problems. J Hum Lact. 2006; 22(3):315-21.

26. Melo AMCA, Cabral PC, Albino E, Moura LMD, Menezes AEB, Wanderley LG. Conhecimentos e atitudes sobre aleitamento materno em primíparas da cidade do Recife, Pernambuco. Rev Bras Saúde Matern Infant. 2002; 2(2):137-42.

27. Brasil. Ministério da Saúde. Sistema de Informação da Atenção Básica - SIAB, Indicadores 2001. 4. ed atualizada, Série G. Estatística e Informação em Saúde. Secretaria de Políticas de Saúde: Brasília; 2003.

28. Excel-97 [computer program]. Version 2003. USA: Microsoft; 2003.

29. SPSS-Estatistical Package [computer program]. Version 13.0. USA: SPSS inc.

30. Weiderpass E, Barros FC, Victora CG, Tomasi E, Halpern R. Incidência e duração da amamentação conforme o tipo de parto: estudo longitudinal no Sul do Brasil. Rev Saúde Publ. 1998; 32(3):225-31.

31. Souza DFRK, Valle MAS, Pacheco MCT. Relação clínica entre hábitos de sucção, má oclusão, aleitamento e grau de informação prévia das mães. Rev Dent Press Ortodon Ortop Facial. 2006; 11(6):81-90.

32. Conselho Regional de Fonoaudiologia São Paulo. Aleitamento materno. [periódico online] 2007. Disponível em: URL:http://www.fonosp.org. $\mathrm{br} /$ publicar/conteudo.php?id=646

Endereço para correspondência:

Rua Industrial, 26

Maceió - AL

CEP: $57080-000$

Tel: (82) 3354-6244

E-mail: ceci_marques@yahoo.com.br 